\title{
Future Projections of Synoptic Weather Types over the Arabian Peninsula during the 21st Century using an Ensemble of CMIP5 Models
}

\author{
Ahmed M. El Kenawy ${ }^{1,2}$ and Matthew F. McCabe ${ }^{1}$ \\ 1. Water Desalinaton and Reuse Center, Division of Biological and Environmental Sciences and Engineering, King Abdullah \\ University of Science and Technology, Thuwal, 23955-6900, Saudi Arabia. \\ 2. Department of Geography, Mansoura University, Mansoura, Egypt. \\ E-mail: (kenawy@mans.edu.eg)
}

\section{Abstract}

An assessment of future change in synoptic conditions over the Arabian Peninsula throughout the $21 \mathrm{st}$ century was performed using 20 climate models from the Coupled Model Intercomparison Project Phase 5 (CMIP5) database. We employed the mean sea level pressure (SLP) data from model output together with NCEP/NCAR reanalysis data and compared the relevant circulation types produced by the Lamb classification scheme for the base period 19752000. Overall, model results illustrated good agreement with the reanalysis, albeit with a tendency to underestimate cyclonic (C) and southeasterly (SE) patterns and to overestimate anticyclones and directional flows. We also investigated future projections for each circulationtype during the rainy season (December-May) using three Representative Concentration Pathways (RCPs), comprising RCP2.6, RCP4.5 and RCP8.5. Overall, two scenarios (RCP4.5 and RCP 8.5) revealed a statistically significant increase in weather types favoring above normal rainfall in the region (e.g., C and E-types). In contrast, weather types associated with lower amounts of rainfall (e.g., anticyclones) are projected to decrease in winter, but increase in spring. For all scenarios, there was consistent agreement on the sign of change (i.e., positive/negative) for the most frequent patterns (e.g., C, SE, E and A-types), whereas the sign was uncertain for less recurrent types (e.g., N, NW, SE and W). The projected changes in weather type frequencies in the region can be viewed not only as indicators of change in rainfall response, but may also be used to inform impact studies pertinent to water resource planning and management, extreme weather analysis and agricultural production.

Key words: Circulation types; Lamb classification; climate models; CMIP5; rainfall; Arabian Peninsula.

\section{Introduction}


Weather types act as an indirect mechanism for understanding the impacts of atmospheric circulation on surface climate, especially during extreme weather events (Papadopoulos et al., 2014). Characterization of weather types can advance our understanding of the complex and large-scale processes that contribute to the weather and climate, not just by providing information that describes and analyzes a wide array of climatologically distinct situations, but also by identifying the location and intensity of particular patterns that govern large-scale synoptic conditions (e.g., cyclones, blockings and zonal advection) (Demuzere et al., 2009; Ramos et al., 2014).

Changes in the rate of occurrence of circulation types are often described as a key driver of changes in climatic variables, such as precipitation (e.g., Hope et al., 2006) and temperature (e.g., Cahynova and Huth, 2009). For this reason, numerous studies have already linked near surface meteorological variables to weather types on different spatial scales, including the local, regional and continental (e.g., Vicente-Serrano and López-Moreno, 2006; Lorenzo et al., 2008, 2011; Hanggi et al., 2011; El Kenawy et al., 2014). For example, Hanggi et al. (2011) assessed the association between changes in weather types and precipitation trends in the boundary region of the Swiss Alps. More recently, El Kenawy et al. (2014) characterized the relationship between weather types and extreme rainfall events over Saudi Arabia for the period 1965-2005, suggesting a generally positive trend in the frequency of weather types associated with dry conditions (e.g., anticyclones and easterly flow) and a general negative trend in patterns favoring above-normal rainfall, such as cyclones.

Numerous methods have already been developed to classify weather types, including pure statistical (e.g., principal components analysis (Esteban et al., 2005), canonical correlation analysis (Xoplakiet et al., 2003) and cluster analysis (Littmann, 2000)), to more dynamic-based methods (e.g., Hess and Brezowsky, 1977). A comprehensive review of different classification methods is given by Huth et al. (2008). Amongst these methods, the automated Lamb classification has been widely used to summarize the state of the climate in a many research efforts (e.g., Trigo and DaCamara, 2000; Vicente-Serrano and López-Moreno, 2006; Lorenzo et al., 2011; Ramos et al., 2011; El Kenawy et al., 2014). The preference for this scheme is generally linked to its robust performance in regions with varied climates, as well as its computational simplicity and limited demands for meteorological data. In addition, this scheme tends to produce more or less physically distinct groups of meteorological situations, in which 
variability within each group is minimized, while variability between groups is maximized (Perez et al., 2014).

With recent developments in the field of climate modeling, data sets from coupled model simulations can provide a unique source to examine potential future changes in circulation patterns (Bauer et al., 2015). In this context, circulation patterns can be very useful for validating climate model outputs as well as predicting their future changes (e.g., Lorenzo et al., 2011; Belleflamme et al., 2013; Cortesi et al., 2013; Perez et al., 2014). One representative example is Lorenzo et al. (2011) who assessed future changes in different synoptic types over the northwest region of the Iberian Peninsula using three different models developed within the Intergovernmental Panel on Climate Change (IPCC) fourth assessment report (IPCC, 2007). Similarly, Perez et al. (2014) assessed the capability of Global Climate Models (GCMs) from the Coupled Model Intercomparison Project Phase 3 (CMIP3) and Phase 5 (CMIP5) for reproducing the synoptic conditions over the northeast Atlantic Ocean region.

In the Middle East, future projections of climate indices have generally been examined within a global context (e.g., Sillmann et al., 2013) or focused regionally on temperature and precipitation (e.g., Evans, 2009; Roshan et al., 2011). For example, Evans (2009) assessed future projections of surface temperature and precipitation over the Middle East, using an ensemble of 18 GCMs under the special report of emissions (SRE A2) scenario. Roshan et al. (2011) also examined temperature projections over Iran using the MAGICC SCENGEN model data under different climate change scenarios. In Saudi Arabia, Almazroui (2013) employed the ECHAM5 A1B emissions scenario to project future (2021-2070) simulations of temperature and precipitation. In contrast, consensus regarding possible future changes of weather types has not received as much attention, with most studies explicitly focused on the occurrence of past or near-present weather types for identifying their frequency and location changes over time (see Alpert et al., 2004; Turkes and Erlat, 2005; Saaroni et al., 2010; El Kenawy et al., 2014).

Assessing potential changes in weather types and characterizing their uncertainties in space and time is required to enhance our understanding of large-scale atmospheric circulations and their associated implications on surface hydrometeorology. This is particularly important in arid and semi-arid areas, such as the Arabian Peninsula, as these regions are especially vulnerable to meteorological extremes such as flash flooding (de Vries et al., 2013; Donat et al., 2014; Deng et al., 2015) and drought, in response to climate variations (Leng et al., 2015). With recent 
advances in global and regional modeling at medium to high resolution, there is an opportunity to determine how the frequency of weather types over the region will change with increasing greenhouse-gas concentrations. Such an assessment is of particular interest because the formation and variability in circulation patterns over the region is strongly influenced by the interrelation between mid-latitude pressure systems and tropical and sub-tropical configurations (Goldreich, 2003; Deng et al. 2015). In addition, local orographic factors (e.g., slope and leeside effect), especially in the southwest mountains, provide marked regional variations as well as drive considerable temporal variability in the hydrometeorology (El Kenawy and McCabe, 2015). All these local and regional scale features can induce a different regional response of climate variables (particularly rainfall) to large-scale circulation.

The main objectives of this work are (i) to evaluate changes in the frequency of circulation types that impact the Arabian Peninsula in the near-present climate by means of a retrospective assessment of an ensemble of 20 models within the CMIP5 project and (ii) to assess how these weather types could be modified under different forcing emission scenarios in the climate of the future. As far as we know, this work represents the first attempt to evaluate the ability of the CMIP5 models in reproducing circulation patterns over the region. This study provides new insights into the characteristics of future weather types in the region, which can be useful for exploring the behavior of a range of surface and atmospheric processes, including extreme weather events and precipitation, wet chemistry, dust deposition, air pollution and many related phenomena.

\section{Study area}

The Arabian Peninsula is located in the southwestern part of Asia, encompassing over 3.2 million $\mathrm{km}^{2}$, with Saudi Arabia representing approximately $80 \%$ of the land area (Figure 1). The climate of the Arabian Peninsula is typically semi-arid to arid, with short, intense, infrequent and unpredictable rainfall events. The annual rainfall of the whole territory is generally below 150 mm (Kwarteng et al., 2009; El Kenawy et al., 2014). Rainfall is mainly distributed during the period from October through April, with April the month of highest rain rate $(18.5 \mathrm{~mm})$ and May and June the lowest rate, with 3.7 and $6.4 \mathrm{~mm}$, respectively. Based on rainfall data for the period 1960-2013, we found that rainfall varies spatially from more than 1,000 mm.year ${ }^{-1}$ in the mountains close to the Red Sea in the southwest corner, to less than $1 \mathrm{~mm}^{\mathrm{year}}{ }^{-1}$ in the Empty Quarter desert region of the southeast. Due to its latitudinal extent, the study domain lies 
between two important and competing global circulations: the subtropical and tropical

137

138

139

140

141

142

143

144

145

146

147 configuration to the south and the mid-latitudinal influences to the north (Figure 1). Accordingly, the study domain is often subjected to different types, frequencies, and magnitudes of airflows, compared to the tropics or high latitudes. Other important local factors affecting climate regimes in the region include orographic uplift, which plays a dominant role in determining the spatial distribution of total rainfall in the southwestern portions. In addition, processes associated with surface heating might present during the summertime, generating rainfall over dry and continental areas.

\section{Data and Methods}

\subsection{Data}

In the following sections, we provide a brief introduction of the different datasets compiled for analysis in this work as well as the methodologies used to construct the weather classification schemes and evaluate the CMIP5 model simulations.

\subsubsection{Reanalysis sea level pressure (SLP) dataset}

In order to compute the circulation types following the Lamb classification (Section 3.2), daily sea level pressure (SLP) data were obtained from the National Center for Environmental Prediction and National Center for Atmospheric Research (NCEP/NCAR) reanalysis project (Kalnay et al., 1996) for the period 1975 to 2000. The selection of this base period is motivated by the notion that the mid 1970s corresponded to a period of a rapid and demonstrable change in the global climate (Brohan et al., 2006). In this work, the NCEP/NCAR reanalysis was preferred to other available global SLP reanalyses (e.g., ERA-Interim and JRA25) as it comprises a longer historical climate reconstruction (Smith and Kummerow, 2013). In addition, this product has been widely evaluated against independent observations (Schoof and Pryor, 2003). Indeed, in their recent study over Saudi Arabia, El Kenawy et al. (2014) confirmed the robustness of the NCEP/NCAR SLP data for a 41-year reference period (1965-2005).

As depicted in Figure 1, the daily SLP data were provided for 16 points at a $2.5^{\circ}$ by $2.5^{\circ}$ spatial interval, covering a region between $5^{\circ}-45^{\circ} \mathrm{N}$ and $30^{\circ}-60^{\circ}$ E. Each of these points represents the centroid of the corresponding grid cell. The selected spatial window encompasses the main configurations governing the climate of the region (e.g., Mediterranean, monsoon, subtropical, tropical and Saharan influences). A conceptually similar approach has been adopted in previous 
related works (e.g., Conway and Jones, 1998; Trigo and DaCamara, 2000; Vicente-Serrano and López-Moreno, 2006; Ramos et al., 2011).

\subsubsection{CMIP5 model output}

To assess changes in the frequency of weather types across the Arabian Peninsula during the 21 st century, our study uses a collection (r1i1p1) of daily SLP data from 20 GCMs. These stateof-the-art coupled GCMs were developed by many modeling groups worldwide and comprise part of the CMIP5 archive, providing information on present and future climates (Taylor et al., 2012). The number of models used in the ensemble was determined according to the availability of SLP data for the analyzed period (1975-2100) and at least two of the investigated scenarios. In particular, we considered future changes in the frequency of weather types by using three core Representative Concentration Pathway (RCP) emission scenarios from the IPCC Fifth Assessment Report (AR5) (IPCC, 2013). These scenarios assume low (RCP2.6), medium (RCP4.5) and high (RCP8.5) rates of radiative forcing by 2100, providing insights into a range of possible future evolutions of atmospheric composition (Moss et al., 2010).

Table 1 lists the model names, resolutions, institutions, and experiments used in this study. Further details on the physics of the CMIP5 models and their experiments can be found at (http://cmip-pcmdi.llnl.gov/cmip5/experiment_design.html) and are documented in Flato et al. (2013). As indicated in Table 1, the investigated CMIP5 models are generally available at a horizontal grid coarser than $1^{\circ}$ latitude by $1^{\circ}$ longitude, with CCSM4 being the model with the finest grid size among the considered models ( $0.94^{\circ}$ latitude by $1.25^{\circ}$ longitude). In this work, SLP data for the defined 16 points (Figure 1) were aggregated from the native grid of each model to a common $2.5^{\circ} \times 2.5^{\circ}$ regular latitude-longitude using a simple arithmetic average of the nearby points, spanning an area identical to the selected NCEP/NCAR region. This procedure was undertaken primarily to account for the different spatial resolution of the CMIP5 models used in this work (Table 1) and to allow for the SLP data to be spatially consistent and accordingly suitable for a fair comparison with NCEP/NCAR reanalysis data. As SLP is not expected to vary considerably over short distances compared to other climate variables (e.g., temperature and precipitation), this approach can provide an adequate representation of SLP variability and their causal processes over the study region (El Kenawy et al., 2014). Here, it should be noted that while a simple local averaging interpolation has been adopted for the SLP in this study, more complicated local interpolation schemes were also examined, including the 
Inverse Distance Weighting (IDW), the bilinear interpolation, the local polynomial and Spline

203

204

205

206

207

208

209

210

211

212

213

214

215

216

217

218

219

220

221

222

223

224

225

226

227

228

229

230

231

232

233

234

235

236

237

238 algorithms. Although not presented here, spatial differences of of SLP configurations were imperceptible and were shown to have negligible impact on the interpolation results.

\subsection{Circulation-type catalogue}

In order to characterize weather types in the region, daily gridded fields of SLP (from NCEP/NCAR reanalysis and CMIP5 models), at the 16 points defined in Figure 1, were used as input for the Lamb weather type scheme (Jones et al., 1993). Following this scheme, the daily circulation was summarized using a set of indices, which are associated with the direction and vorticity of the geostrophic flow. These indices included southerly flow (SF), westerly flow (WF), total flow (F), westerly shear vorticity (ZW), southerly shear vorticity (ZS) and total shear vorticity $(Z)$. These indices were computed from the 16 grid points shown in Figure 1, as follows:

$$
\begin{aligned}
& \mathrm{SF}=1.35(0.25(\mathrm{P} 5+2 \mathrm{P} 9+\mathrm{P} 13)-0.25(\mathrm{P} 4+2 \mathrm{P} 8+\mathrm{P} 12)) \\
& W F=(0.5(\mathrm{P} 12+\mathrm{P} 13)-0.5(\mathrm{P} 4+\mathrm{P} 5)) \\
& \mathrm{ZS}=0.85[0.25(\mathrm{P} 6+2 \mathrm{P} 10+\mathrm{P} 14)-0.25(\mathrm{P} 5+2 \mathrm{P} 9+\mathrm{P} 13)] \\
& -0.25(\mathrm{P} 4+2 \mathrm{P} 8+\mathrm{P} 12)+0.25(\mathrm{P} 3+2 \mathrm{P} 7+\mathrm{P} 11)) \\
& \mathrm{ZW}=1.12[0.5(\mathrm{P} 15+\mathrm{P} 16]-0.5(\mathrm{P} 8+\mathrm{P} 9)] \\
& -0.91(0.5(\mathrm{P} 8+\mathrm{P} 9)-0.5(\mathrm{P} 1+\mathrm{P} 2)) \\
& \mathrm{F}=\left(\mathrm{SF}^{2}+\mathrm{WF}^{2}\right)^{0.5} \\
& \mathrm{Z}=\mathrm{ZS}+\mathrm{ZW}
\end{aligned}
$$

Weather types were then defined on a daily basis, as a function of $\mathrm{Z}$ and $\mathrm{F}$ values, following Table 2. According to the Lamb classification scheme, a set of 26 different weather types was initially defined: two non-directional (anticyclones (A) and cyclonic (C)), eight pure directional $(\mathrm{N}, \mathrm{S}, \mathrm{E}, \mathrm{W}, \mathrm{NW}, \mathrm{SW}, \mathrm{SE}$ and $\mathrm{NE})$ and sixteen "hybrid" types, which combined the nondirectional and pure directional types (i.e., AN, AS, AE, AW, ANW, ASW, ASE, ANE, CN, $\mathrm{CS}, \mathrm{CE}, \mathrm{CW}, \mathrm{CNW}, \mathrm{CSW}, \mathrm{CSE}$ and CNE). For directional types, the direction was determined according to arctan (WF/SF), adding $180^{\circ}$ if WF is positive (Goodess, 2000). 
To simplify the outputs of the classification, we aggregated weather types into fewer and more

240

241

242

243

244

245

246

247

248

249

250

251

252

253

254

255

256

257

258

259

260

261

262

263

264

265

266

267

268

269

270

271

272

meaningful groups according to their directions. More specifically, given that the frequencies of the 16 hybrid types are expected to be relatively small compared to other types- as differences in occurrence within one direction (including both cyclonic and anticyclonic types) are likely to be smaller compared to the differences between types of varying directions- we eliminated hybrid types by reclassifying them into synoptic (C/A) and directional (NE, SE, NW, SW, E, W, N, S). For example, the CSW-type was reclassified as $50 \%$ cyclonic (C) and $50 \% \mathrm{SW}$. Many studies have adopted the same approach to facilitate inter-comparison amongst the different weather types (see, for example, Trigo and DaCamara, 2000; Demuzere et al., 2009; Lorenz et al., 2011). Overall, this procedure resulted in a maximum of ten groups: eight directional, a cyclonic (C) and an anticyclonic (A).

\subsection{Model evaluation}

Prior to the analysis of future climate simulations, it was important to establish the capability of the CMIP5 models to reproduce the near-present weather types by undertaking a retrospective assessment. To accomplish this task, we compared the frequencies of the weather types in the so-called "historical" simulations with those obtained from the NCEP/NCAR reanalysis dataset. Here, we restricted the evaluation procedure to the reference period from 1975 to 2000, which is a period of common historical data for reanalysis and all CMIP5 model data. The skill of GCMs to replicate the synoptic conditions was assessed for winter (December-February; DJF) and spring (March-May; MAM). The selection of the two rainy seasons over the region is motivated by two reasons. First, rainfall is an important climate variable in arid and semi-arid regions, as rainfall is generally scarce, unpredictable and highly variable in space and time. Second, other seasons (e.g., summer) are characterized by a disproportionate frequency of cyclonic circulation over the peninsula, in relation to a very infrequent occurrence of other circulation patterns (El Kenawy et al., 2014).

Model responses were analyzed according to their capacity to reproduce the near-present seasonal characteristics of weather types (i.e., mean frequency and variance). In principle, the performance of each model was assessed via the use of three metrics, which together provide a more rigorous evaluation of the model uncertainty. These estimators included the bias, the scatter index (SI) and the standard deviation scatter index (stdevSI). While the bias is a measure of the average difference between observed and modeled data, SI is a normalized measure of the error between observed and simulated climate (Clancy et al. 1986). On the other hand, stdevSI 
273 is a measure of bias in variability, as it uses the difference between the standard deviation

274 (stdev) of observed and modeled data (Perez et al., 2014). Lower values of SI and stdevSI

275 suggest better agreement between observed and model data and hence a better performing

276 GCM.

277

278 The evaluation metrics were calculated independently for each weather type during the period 1975-2000, and formulated as:

280

Bias $=n^{-1} \sum_{i=1}^{n}\left(P_{i}-O_{i}\right)$

$282 \quad S I=\sqrt{\frac{\sum_{i=1}^{n}\left(O_{i}^{\prime}-P_{i}^{\prime}\right)^{2}}{N}} / \frac{\sum_{i=1}^{n}\left(O_{i}^{\prime}\right)}{N}$

$283 \quad s t d e v S I=\sqrt{\frac{\sum_{i=1}^{n}\left(\operatorname{stdev}\left(O_{i}^{\prime}\right)-\operatorname{stdev}\left(P_{i}^{\prime}\right)\right)^{2}}{N}} / \frac{\sum_{i=1}^{n}\left(\operatorname{stdev}\left(O_{i}^{\prime}\right)\right)}{N}$

284

285

286

287

288

289

290

291

292

293

294

295

296

297

298

299

where $n$ is the length of the time series (in this case $26 \mathrm{yr}$ ), $O$ is the mean frequency of a particular weather type in the reanalysis, $P$ is the mean frequency of the same weather type in the model, and $i$ is the index for year, $\mathrm{O}^{\prime}$ is the relative frequency of the $i^{\text {th }}$ weather type from the reanalysis over the base period, $\mathrm{P}^{\prime}$ is the relative frequency of the $i^{\text {th }}$ weather type from a GCM simulation for the base period and $N$ is the number of weather types.

To measure the overall skill of each model, we used a single metric that aggregates several statistical measures (i.e., mean and standard deviation). This estimator allows for ranking the models according to their overall respective performance in replicating not just the mean frequency of the weather types, but also their standard deviation. The ranking procedure is summarized in the following steps:

1. The degree of agreement (DAmean) between each model and the reanalysis in terms of replicating the mean frequency of each weather type during the base period (1975-2000) was computed following the modified equation of Huang et al. (2014), as:

DAmean $=\left[\frac{1}{c} \sum_{i=1}^{c}\left(\frac{\bar{P}_{i}}{\bar{O}_{i}-1}\right)^{2}\right]^{0.5}$ 

for the base period and $c$ refers to the count of the models used in this study.

303

304

305

306

307

308

2. The degree of agreement (DAstdev) in terms of replicating standard deviation of each weather type was calculated in a manner similar to Eq.10, as:

$$
\text { DAstdev }=\left[\frac{1}{c} \sum_{i=1}^{c}\left(\frac{\overline{\text { Pstdev }}_{i}}{\overline{\text { Ostdev }}_{i}-1}\right)^{2}\right]^{0.5}
$$

where $\overline{P s t d e v}$ is the standard deviation of the $i^{\text {th }}$ weather type from a GCM simulation, $\overline{\text { Ostdev }}$ is the standard deviation of the $i^{\text {th }}$ weather type from the reanalysis and $c$ refers to the count of the models used in this study.

3. For each weather type, we ranked the models according to the $\mathrm{DA}_{\text {mean }}$ value from highest to lowest, with the sequence numbers ranging from 1 to 20 (seq 1 to seq20). We also ranked the models according to their DAstdev values in a similar fashion.

4. We scored each models ability to reproduce the mean frequency of each weather type using the sequence number (seq) obtained in step 3. In particular, for the model with the $i^{\text {th }}$ sequence number with respect to $\mathrm{D}_{\text {mean }}$, the score $(\mathrm{S})$ was given as:

$\mathrm{S}=\frac{\mathrm{seq}_{\mathrm{i}}-1}{\mathrm{c}-1}$

where seq is the sequence number of each model and $c$ is the total count of the models. The calculations were repeated for $\mathrm{DA}_{\text {stdev. }}$

5. Finally, we calculated the overall score $(O S)$ of each model by averaging the two score values obtained in step 4 (one for $\mathrm{DA}_{\text {mean }}$ and the other is for $\mathrm{DA}_{\text {stdev }}$ ). The $O S$ values vary from 0 (no skill) to 1 (perfect skill).

A similar procedure was recently applied in Huang et al. (2014) to validate precipitation characteristics (e.g., mean, standard deviation and trends) derived from the CRU TS3.10 data set against those of CMIP5 model output over central Asia.

\subsection{Future projections of weather types}


For the 21st century, we assessed future projections in the mean frequency of weather types for

331

332

333

334

335

336

337

338

339

340

341

342

343

344

345

346

347

348

349

350

351

352

353

354

355

356

357

358

359

360

361

362 the mid (2035-2060) and late (2075-2100) century, by comparing the simulated frequency of each weather type for each ensemble member with the frequency obtained from the reference period simulation (1975-2000). These changes were expressed in relative terms (\% of days), showing how the frequencies of weather types in a particular year depart from the mean behavior. The statistical significance of the obtained differences between the base period and future simulations was tested using the non-parametric Wilcoxon signed-rank test at the 5\% significance level (Wilks, 2011).

In order to improve GCM predictions and to reduce the simulation uncertainty (e.g., from scale issues, resolution, parameterization of physical processes and natural variability), we calculated a multi-model mean from the CMIP5 ensemble by taking the average of the 20 model members used in this work. The multi-model ensemble approach has been shown in many studies to outperform individual models, as they provide more robust estimates of future projections and their related uncertainties (see Evans, 2009; Sillmann et al., 2013; El Kenawy et al., 2015). However, recalling that the models may respond differently to a specific radiative forcing as a consequence of varying model-specific climate sensitivities, we were also interested in exploring the model uncertainty through measuring the dispersion (spread) of GCMs around their centroid using the inter-model variability (in percent).

\section{Results and Discussion}

\subsection{Retrospective model evaluation}

In order to determine how well the models reproduce the observed circulation types, we compared weather type frequencies calculated from the NCEP/NCAR data and GCM control runs using a set of statistical measures (e.g., bias, SI and stdevSI) (Section 3.3). Figure 2 summarizes the relative frequency of each synoptic circulation type for the NCEP/NCAR reanalysis, together with each individual model and the multi-model mean during winter (DJF) and spring (MAM). Overall, there is generally good agreement for circulation occurrence between NCEP/NCAR data and CMIP5 models, with a large proportion of $\mathrm{C}$ type, in addition to flows coming mainly from $\mathrm{E}$ and SE. This response is evident in winter and spring. However, there are also some considerable discrepancies for specific weather types. In winter, A-types contribute to $12.3 \%$ of winter days in the reanalysis, which deviates substantially from the ensemble mean (40.1\%). Model data suggest winter as the predominant season for anticyclonic 
activity over the peninsula, but with a large spread, with the occurrence of A-type considerably varying from $11.2 \%$ in MIROC5 to $61.6 \%$ in BNU-ESM. In contrast, results show small differences in the E-type relative frequency between the reanalysis and CMIP5 climate models, as the relative frequency of $\mathrm{E}$ days is $14.4 \%$ in the reanalysis during winter, compared to $17.2 \%$ for the multi-model mean.

In spring, the results of the reanalysis and the ensemble mean suggested C-type as the dominant circulation pattern, with $66.6 \%$ and $58.1 \%$ of all days, respectively. Similar to A-type in winter, the spread of the model for the key circulation (C-type) is quite large, with values ranging from $41 \%$ for GFDL-ESM2M to $80.2 \%$ for MIROC5. The most skilled GCMs in replicating the relative frequency of C-type in spring are MPI-ESM-LR, CNRM-CM5 and HadGEM2-ES, with $65.8 \%, 65.7 \%$ and $65.1 \%$ of days, respectively. Again, the CMIP5 ensemble is skillful in reproducing the relative frequency of E-type with small error (the ensemble mean $=9.7 \%$ and the reanalysis $=6.4 \%$ ). Indeed, there are many models where the relative frequency of E days is much closer to the reanalysis (e.g., INM-CM4 (6.6\%), MRI-CGCM3 (6.9\%), MPI-ESM-LR (7.3\%), MPI-ESM-MR (7.5\%) and CCSM4 (5.4\%)).

Figure 3 displays uncertainties in climate model simulations, as revealed by the overall biases. The bias is presented here as the differences between the mean monthly circulation-type frequencies (in days). A quick inspection of Figure 3 reveals that the model suggests some differences in the general circulation system produced by the reanalysis data, with a clear tendency to under-predict $\mathrm{C}$ and SE-types, while over-predicting other types. For example, A days are overestimated by 24.9 days during winter months, which is equal to $27.7 \%$ of days per season. In contrast, the $\mathrm{C}$ days count is underestimated by 11.6 days (12.9\% of winter days). In winter, the CMIP5 ensemble is capable of reproducing NE and N circulation patterns, while they fail to reproduce the majority of patterns, including southern (SE, S and SW), western (NW and $\mathrm{W}$ ) and anticyclonic (A). Again, our analysis confirms that flows coming from the east (Etype) are best reproduced in the first half of the year (winter and spring).

Figure 4 illustrates the performance of each single model in simulating the mean frequency of weather types during the period 1975-2000, as summarized by the scatter index (SI), with the lower values indicating a better performing GCM. Although this index is a difference-based metric like the bias, it provides improved indications on the performance of the GCMs, given 
of weather types (Clancy et al. 1986). In winter, the results reveal that the models are more skillful in replicating all types, apart from $\mathrm{C}$ and SE-types, where only relatively few members can reproduce the mean frequencies of the near-present (1970-2000) period. For C-type, MPIESM-LR, CSIRO-Mk3-6-0 and MPI-ESM-MR are the most skillful models in capturing the mean frequency. For SE-type, the lowest values of SI (and hence the best agreement) are obtained for GFDL-CM3, HadGEM2-ES, CanESM2 and MIROC5. As illustrated in Figure 4, the mean frequency of $\mathrm{C}, \mathrm{SE}$ and S-types is poorly reproduced by a particular range of CMIP5 models (CCSM4, IPSL-CM5A-MR, IPSL-CM5A-LR and NorESM1-M). For spring, the performance of the CMIP5 models is improved relative to the winter. Specifically, the circulation patterns with higher frequency (e.g., C, SE, E and A) are generally well reproduced by the model data, compared to the less frequent types (e.g., N, NW, SW and W), which show considerable discrepancies. For example, $\mathrm{C}$ days are reproduced well by the majority of the ensemble members, with some of them presenting almost perfect skill (e.g., MPI-ESM-LR $(\mathrm{SI}=0.04)$ and CNRM-CM5 (SI=0.05)). As illustrated in Figure 4, MIROC5, MIROC-ESM and MIROC-ESM-CHEM show considerable differences from the reanalysis data for the SE, E and A circulation types (SI >3.5).

Figure 5 depicts the standard deviation scatter index (stdevSI) estimated for the 26-yr period (1975-2000) for each circulation type. In accordance with the results on the frequency of the ten circulation patterns (Figure 4), stdevSI values indicate that the variability of the majority of weather types is well reproduced by the individual models. As depicted, circulation patterns are well represented in the CMIP5 climate simulations for most types and seasons. However, there are well-marked variations in the standard deviation of C-type in winter, $\mathrm{W}$ and SW-types in spring and the pure southerly flows in both seasons. For particular types (e.g., S), the models that fail to replicate the mean frequency show low skill in reproducing the standard deviation (see, for example, CCSM4, IPSL-CM5A-MR and IPSL-CM5A-LR). Conversely, for other types (e.g., SE flows), the skill of particular members (e.g., BNU-ESM, MIROC-ESM and MIROC-ESM-CHEM) in simulating the standard deviation of circulation types, improves markedly compared to their capacity to reproduce the mean frequency.

Overall, a visual comparison of Figures 4 and 5 reveals that the temporal characteristics (mean frequency and standard deviation) of the weather types in the CMIP5 models match closely to those found in NCEP/NCAR, despite some small differences. In effect, apart from SE and S- 
by the CMIP5 climate simulations during the base period of 1975-2000. Importantly, the results

432

433

434

435

436

437

438

439

440

441

442

443

444

445

indicate that the increasing spatial resolution of the CMIP5 members may have an impact on the ability of the models to reproduce the present climate as, on some occasions, the simulated circulation patterns are improved as the underlying model resolution increases. For example, some models with a relatively fine spatial interval, such as CNRM-CM5 (1.4 lat $\times 1.4^{\circ}$ lon), CCSM4 $\left(0.94^{\circ}\right.$ lat $\times 1.25^{\circ}$ lon $)$ and CNRM-CM5 $\left(1.4^{\circ}\right.$ lat $\times 1.4^{\circ}$ lon $)$ show improved skill in reproducing circulation patterns in retrospective simulations, compared to other relatively coarse resolution members (e.g., BCC-CSM1-1, BNU-ESM, CanESM2 and MIROC-ESM (2.8 lat $\times 2.8^{\circ}$ lon)). One of the sources of these differences may be that both the reanalysis and models represent spatially averaged SLP data, which may make the pressure systems more smoothed in lower resolution GCMs when compared to the reanalysis $\left(2.5^{\circ}\right.$ lat $\times 2.5^{\circ}$ lon $)$. In addition, it should be noted that the CMIP5 uses different sets of GCMs, with varying physics schemes (e.g., clouds, boundary layer land surface processes), which may pose an additional source of uncertainty in addressing comparisons between model simulations (Taylor et al., 2012; Sillmann et al., 2013; Perez et al., 2014). However, it should be emphasized that the possible role of spatial resolution on a model's ability to reproduce the mean frequency of weather types requires further investigation. This is particularly because SLP is a field that naturally exhibits smooth and large scale spatial variations.

In an attempt to rank the individual models according to their capacity to replicate both the mean and standard deviation of weather types over the base period, we applied the methodology detailed in Section 3.3. The overall score (OS) of the ensemble members for each weather type is summarized in Figure 6, with 0 referring to no skill and 1 representing a perfect skill. The results indicate clearly that the ranking of GCMs differs from one weather type to another. Nonetheless, the results suggest that MPI-ESM-LR outperforms all other models in terms of simulating the temporal characteristics of cyclonic conditions (OS=0.93), while MIROC5 is the most skillful model in reproducing $A$ and $N E(O S=0.99)$ and $N(O S=0.90)$ circulations. Good results are also obtained for $\mathrm{A}$ and SE-types using CanESM2 simulations, whereas CNRMCM5 is a noticeably poor-performing model for replicating $\mathrm{N}$ and $\mathrm{NW}$ flows in the region. As illustrated in Figure 6, for particular patterns (e.g., SE, A, S, NE and W), the spread among the CMIP5 ensemble members in terms of their overall skill tends to be more variable, while there are smaller inter-model variations for other patterns (e.g., E and SW). In general, it is evident that no single model could replicate the characteristics of all weather types equally well. This finding suggests that an ensemble that combines all members or even an ensemble of high- 
performing models is likely to outperform any single model. In their assessment of the performance of the CMIP3 models to simulate tropospheric stability over the Arabian Peninsula, Barfus and Bernhofer (2014) found a large spread among model output, noting that no single model can outperform any other. Similarly, in a study over the Middle East, Evans (2009) concluded that the performance of GCMs in simulating precipitation characteristics varies considerably, with no outstanding model able to be identified.

\subsection{Projected changes in the frequency of weather types}

To assess projected changes in the frequency of each defined weather type, relative changes ( $\%$ of days) were defined by comparing the mean frequency for the control run (1975-2000) with those of the two 26-year future periods (2035-2060 and 2075-2100). Figure 7 presents projected changes in the seasonal frequencies of weather types for the period 2035-2060 using the 20model ensemble mean, illustrating both inter-annual and inter-scenario variability. The results suggest more significant changes in the frequencies of weather types for RCP8.5 compared to the low (RCP2.6) and medium (RCP4.5) emission scenarios. This feature can be clearly observed during winter (DJF), with almost all weather types showing statistically significant changes for RCP8.5 (following Wilcoxon signed-rank test at $\mathrm{p}<0.05$ ). On the other hand, significant changes were identified for only five patterns using RCP2.6 and seven for the RCP4.5 scenarios. Further, the results indicate that all RCPs project a decrease in the frequency of $\mathrm{C}$ days in spring, a result that is completely reversed in the winter. This finding is interesting given that $\mathrm{C}$-type is the pattern with the highest frequency in spring. For the most frequent circulation patterns (e.g., C, SE, E, A and S), the results suggest good agreement on the sign of change (i.e., positive/negative) between the three scenarios in both seasons. This could be related to the better agreement on the sign of change among models (see Figure 9). In contrast, there is a considerable discrepancy in the sign of change for the less frequent types (e.g., N, SW, $\mathrm{NW}$ and $\mathrm{W}$ ).

In winter, the ensemble mean suggests a strong positive relative change in the frequency of $\mathrm{E}$ and NE- types in the near-future simulations. For example, type E day-counts are likely to increase by $20.3 \%, 20.7 \%$ and $21.3 \%$ in RCP2.6, RCP4.5 and RCP8.5 scenarios, respectively. On the other hand, A, S, N and NW-types show negative relative change, albeit being statistically insignificant at the 95\% confidence interval for two scenarios (RCP2.6 and RCP4.5). With respect to the westerly flows (e.g., SW, NW and W), which are the least 
frequent patterns, RCP2.6 and RCP8.5 project a decrease in their frequencies, with relative anomalies ranging between $-11.1 \%(\mathrm{NW}, \mathrm{RCP} 8.5)$ and $-29.8 \%$ (SW, RCP8.5). For the most frequent types (i.e., SE and C-types), the results are inconsistent among all scenarios. Specifically, SE days tend to increase slightly (0.5\%) following RCP2.6 simulations, while RCP4.5 and RCP8.5 suggest a decrease in their count by $-10.7 \%$ and $-4.5 \%$, respectively. During the 2035-2060 period, a weak decrease in the frequency of C-types is projected according to RCP2.6 (-1.1\%): a behavior that is likely to be reversed for RCP4.5 (4.2\%) and RCP8.5 (4.4\%). In their recent assessment of the association between weather type occurrence and rainfall characteristics over Saudi Arabia, El Kenawy et al. (2014) demonstrated that C-type explained $33.2 \%$ of the winter total amounts of rainfall and $33.4 \%$ of the total rain-days during winter months. Hence, the projected increase in the cyclonic conditions in winter, as suggested by at least two scenarios (RCP4.5 and RCP8.5), may imply a tendency towards increasing winter rainfall in the mid-century climate over the region.

Similar to winter (DJF), the significant changes in the mean frequency of weather types during spring (MAM) are higher for RCP8.5 than for RCP2.6 and RCP4.5 scenarios. In spring, all scenarios agree on an increase in E, A and NE circulation types. However, the results show a projected decrease in the frequency of $\mathrm{C}, \mathrm{S}$ and $\mathrm{N}$-types. Among all circulation patterns, RCP2.6 and RCP4.5 scenarios reveal a statistically significant decrease in the SW and an increase in the E pattern $(\mathrm{p}<0.05)$. In contrast to winter, all scenarios suggest a decrease in the frequency of C-type during springtime, by $-10.7 \%$ (RCP2.6), -0.9\% (RCP4.5) and -1.2\% (RCP8.5), though being statistically insignificant in all cases $(\mathrm{p}<0.05)$. period, with respect to those of the 1975-2000 period. Similar to the 2035-2060 simulations, the results for the end of the 21st century show more significant changes for RCP8.5 simulations than for RCP2.6 and RCP4.5. According to RCP2.6 and RCP8.5, the majority of weather types show a decrease in frequency during the latter part of the century, although not all of these changes are statistically significant $(\mathrm{p}<0.05)$. Nonetheless, all scenarios confirm more significant changes in the circulation patterns during winter, compared to spring. For all scenarios, the results suggest an increase in the frequency of $\mathrm{E}$ and NE circulation types, while

529 the occurrence of SE, A, S and NW will be reduced. In contrast to RCP2.6, the RCP4.5 and 530 RCP8.5 simulations suggest a significant increase in the mean frequency of cyclones during 
winter. In spring, RCP8.5 leads to a significant increase in the frequency of C and E-types,

532

533

534

535

536

537

538

539

540

541

542

543

544

545

546

547

548

549

550

551

552

553

554

555

556

557

558

559

560

561

562

563

564 while there would be a significant decline in the frequency of southerly and westerly types.

A comparison of Figures 7 and 8 reveals that some circulation patterns favoring above-normal rainfall (e.g., C and E-types) tend to show positive change during the rainy seasons (DecemberMay), with changes in the latter period (2075-2100) being larger than those for the mid-century climate. For example, for the period 2075-2100, RCP8.5 predicts an increase in the occurrence of C-type by $14.3 \%$ by the end of this century, compared to only $4.4 \%$ for the period 2035 2060. Such a response would suggest an increase in the probability of rainfall, due to the fact that C-type is one of the most important circulation patterns explaining winter rainfall in the study domain (El Kenawy et al., 2014). Another above-normal rainfall type (i.e., E-type) is also projected to increase in the mid-century climate by $21.3 \%$ in RCP8.5, compared to $35.3 \%$ at the end of the century. In contrast, weather types associated more with below-normal rainfall in the region (e.g., A and N-types) are likely to decrease in all future simulations, particularly during winter. For the near-future simulations in Figure 7, anticyclonic conditions are likely to be reduced during winter by $-8.5 \%$ ( $\mathrm{RCP} 2.6),-5.5 \%$ ( $\mathrm{RCP} 4.5)$ and $-7.9 \%$ (RCP8.5). By the end of the century, the ensemble mean predicts a reduction in A days of -7.9\% (RCP2.6), $-9.3 \%$ (RCP4.5) and -15.7\% (RCP8.5). Given that A-type is the most important circulation pattern associating with negative anomalies of rainfall in the mid latitudes (Vicente-Serrano and LopezMoreno, 2006), our findings suggest that the study domain might be prone to more frequent rainfall events in the future, particularly for the latter period of the century. Interestingly, in a recent study by El Kenawy et al., (2014) for a near-present (1960-2005) climate assessment over Saudi Arabia, A-types were observed to increase over the last few decades. Further understanding of the physical processes driving such potential changes into the future is clearly required. Nonetheless, the results agree with the relatively limited number of future projection studies undertaken over the region. A representative investigation is that of Almazroui (2013), who indicated that rainy regions of Saudi Arabia, especially along the central parts of the Red Sea and the southwestern areas, may experience more extreme rainfall events in the future. This result is also reflected in the study of Evans (2009) who noted that, by the late part of the 21st century, precipitation amount is likely to increase over eastern and western parts of the Arabian Peninsula on the order of 5-15 mm.year ${ }^{-1}$. Similarly, the IPCC 5th ARR (2013) shows that precipitation is likely to increase by $20-60 \%$ (RCP8.5) at the end of the 21 st century over the Arabian Peninsula, relative to the 1986-2005 control period. Notably, although the radiative forcing prescribed in the RCP scenarios can lead to different responses in the circulation 
patterns, Figures 7 and 8 indicate that all RCPs predictions generally agree on the direction of changes (i.e., positive/negative) for the most frequent types (e.g., C, SE, E, A and S types). In comparison, the three emission scenarios show an opposite sign of change for the least frequent patterns (e.g., N, SW, NW and W), suggesting larger uncertainty for these patterns in many instances.

\subsection{Inter-model and inter-scenario variability}

While understanding individual or ensemble model response to future changes is important for establishing likely climate behavior, it is equally important to examine the spread of the CMIP5 models and their variations in terms of the response to the three different RCP scenarios. Such an assessment can offer insights not just into the uncertainties associated with the future, but also the forcing and parametric uncertainty introduced in the range of CMIP5 members used in this study.

Figure 9 shows the multi-model spread for changes in the frequency of circulation patterns for the near- and far-future simulations, respectively, relative to the base period. The results present only the five most frequent classification types, which are also associated more closely with the potential for environmental and socio-economic impact in the region. Focusing on the 20352060 period, it can be seen that the projected model spread of results differ across the three future emission scenarios, among seasons and between circulation patterns. In terms of the inter-quartile spread, the circulation projections generated by RCP8.5 are generally smaller when compared to those of RCP2.6 and RCP4.5. Seasonally, it can be noted that the sign of the inter-quartile range is mostly consistent between winter and spring, particularly for the most frequent types (i.e., C, SE and E). In Figure 9, we also examine the inter-model spread during the period 2075-2100. In accordance with the future projections for the period 2035-2060 and for the majority of weather types, there is a consistent trend towards larger changes, either positive or negative, in RCP8.5 than in RCP2.6 and RCP4.5. Similar to the mid-century future projections, the inter-quartile range for all scenarios is larger in SE and E types, compared to other weather types.

\section{Conclusions}

596

Using the SLP data derived from 20 ensemble members of GCMs forming part of the CMIP5 597 archive, this study aimed to assess developments in near-present and future projections of 
circulation types over the Arabian Peninsula: a region of joint influences of the tropical and

599

600

601

602

603

604

605

606

607

608

609

610

611

612

613

614

615

616

617

618

619

620

621

622

623

624

625

626

627

628

629

630

631 extra-tropical configurations. We defined weather types as an abstraction of the mean SLP field, since GCMs do not simulate weather types directly. Based on an automated version of the Lamb weather type classification scheme, the ability of the CMIP5 models to reproduce the nearpresent climate (1975-2000) was evaluated. In particular, the frequency of occurrence for ten weather types (i.e., cyclonic, anticyclonic and eight flow directional types) calculated using the CMIP5 ensemble were evaluated against those derived from the NCEP/NCAR reanalysis. In general, the validation results indicate that the CMIP5 SLP data yielded similar circulation patterns to those found in the NCEP/NCAR reanalysis data. CMIP5 models were generally able to simulate the mean frequency and standard deviation of weather patterns, as represented by the scatter index (SI) and scatter index of standard deviation (stedvSI), providing a degree of confidence in future projections of circulation patterns derived from the CMIP5 models.

Projected climate changes in the frequency of circulation patterns were assessed using a multimodel ensemble approach for two future time slices: 2035-2060 and 2075-2100, under a range of emission scenarios (RCP2.6, RCP4.5 and RCP8.5). As anticipated, results indicate that the high concentration pathway (RCP8.5) is associated with the most significant changes, particularly over the latter decades of the century, compared to the moderate (RCP4.5) and lower (RCP2.6) transient pathways of anthropogenic emissions. The CMIP5-based projections of change also suggest significant increases in the frequency of above-normal rainfall types in the region (e.g., cyclonic and E flows), while there is likely to be a decrease in patterns linked to below-normal rainfall (e.g., anticyclones). Our results also indicate that all models and scenarios agree on greater changes in the frequency of all weather types by the end of the 21st century, compared to the near-future changes (2035-2060), as well as in winter compared to spring.

The present study provides an overview of how circulation types will respond to climate changes in the future over the Arabian Peninsula using different emission scenarios and multimodel ensembles from the CMIP5 database, providing evidence that the CMIP5 model database offers valuable information on weather types. Results generally indicate that the CMIP5 models with higher spatial resolution tended to show better performance, compared to models with a coarser resolution. However, further analysis is required to comprehensively investigate the impact of the spatial resolution on the skill of the GCM in reproducing circulation patterns in the region. Additional analyses on the mechanisms (e.g., SLP differences in model simulations) driving these projected changes in weather types, an aspect that is beyond the scope of the 
current research, is an area of needed investigation. In the same context, examining future regional changes in rainfall and temperature under different scenarios and attributing these to changes in weather types would benefit a greater understanding of these processes. Improved process understanding is especially important in arid and semi-arid regions such as the Arabian Peninsula, where both natural and human environments are impacted disproportionally to even small changes in climate (and rainfall) variability.

\section{Acknowledgements}

Research reported in this publication was supported by the King Abdullah University of Science and Technology (KAUST), Saudi Arabia. We wish to thank the various international modeling groups for providing their data through the CMIP5 initiative. We also would like to thank the NOAA/OAR/ESRL PSD, Boulder, Colorado, USA for providing the NCEP reanalysis data.

\section{References}

Almazroui, M. (2013), Simulation of present and future climate of Saudi Arabia using a regional climate model (PRECIS), International Journal of Climatology, 33 (9), 22472259.

Alpert, P., Osetinsky, I., Ziv, B., and Shafir, H. (2004), Semi-objective classification for daily synoptic systems: application to the eastern Mediterranean climate change, International Journal of Climatology, 24 (8), 1001-1011.

Barfus, K., and Bernhofer, C. (2014), Assessment of GCM capabilities to simulate tropospheric stability on the Arabian Peninsula, International Journal of Climatology, doi:10.1002/joc.4092.

Bauer, P., Thorpe, A., Brunet, G. (2015), The quiet revolution of numerical weather prediction, , 525(7567):47-55. doi: 10.1038/nature14956.

Belleflamme, A., Fettweis, X., Lang, C., and Erpicum, M. (2013), Current and future atmospheric circulation at $500 \mathrm{hPa}$ over Greenland simulated by the CMIP3 and CMIP5 global models, Clim Dyn, 41 (7-8), 2061-2080.

Brohan, P., Kennedy, J.J., Harris, I., Tett, S.F.B., and Jones, P.D. (2006), Uncertainty estimates in regional and global observed temperature changes: A new data set from 1850, Journal of Geoph. Res.: Atmospheres, 111(D12), doi:10.1029/2005JD006548.

Cahynová, M., and Huth, R. (2009), Changes of atmospheric circulation in central Europe and their influence on climatic trends in the Czech Republic, Theor Appl Climatol, 96 (1-2), 57-68.

Clancy, R., Kaitala, J. E., and ambresky, L. F. (1986), The Fleet Numerical Oceanography Center Global Spectral Ocean Wave Model, Bull. Amer. Meteor. Soc., 67, 498-512.

Conway, D. and Jones, P. D. (1998), The use of weather types and air flow indices for GCM downscaling, Journal of Hydrology, 212-213, 348-361.

Cortesi, N., Trigo, R. M., Gonzalez-Hidalgo, J. C., and Ramos, A. M. (2013), Modelling monthly precipitation with circulation weather types for a dense network of stations over Iberia, Hydrol. Earth Syst. Sci., 17, 665-678. 
de Vries, A. J., Tyrlis, E., Edry, D., Krichak, S. O., Steil, B., and Lelieveld, J. (2013), Extreme precipitation events in the Middle East: Dynamics of the Active Red Sea Trough, Journal of Geophysical Research: Atmospheres, 118 (13), 7087-7108.

Demuzere, M., M. Werner, N. P. M. van Lipzig, and E. Roeckner (2009), An analysis of present and future ECHAM5 pressure fields using a classification of circulation patterns, International Journal of Climatology, 29 (12), 1796-1810.

Deng, L., McCabe, M. F., Stenchikov, G., Evans, J. P., and Kucera, P. A. (2015), Simulation of flash-flood-producing storm events in Saudi Arabia using the weather research and forecasting model, J. Hydrometeorology, 16, 615-630.

Donat, M. G., et al. (2014), Changes in extreme temperature and precipitation in the Arab region: long-term trends and variability related to ENSO and NAO, International Journal of Climatology, 34 (3), 581-592.

El Kenawy, A. M., McCabe, M. F., Stenchikov, G., and Raj, J. (2014), Multi-Decadal Classification of Synoptic Weather Types, Observed Trends and Links to Rainfall Characteristics over Saudi Arabia, Frontiers in Environmental Science, 2, doi: 10.3389/fenvs.2014.00037.

Esteban, P., Jones, P. J., Martín-Vide, J., and Mases, M. (2005), Atmospheric circulation patterns related to heavy snowfall days in Andorra, Pyrenees, International Journal of Climatology, 25 (3), 319-329.

Evans, J. P. (2009), 21st century climate change in the Middle East, Climatic Change, 92, 417432.

Flato G, Marotzke J, Abiodun B, Braconnot P, Chou SC, Collins W, Cox P, et al. (2013) Evaluation of climate models. In: Climate change 2013: The Physical science basis. Working Group I contribution to the fifth assessment report of the intergovernmental panel on climate change, Tech. rep., Groupe d'experts intergouvernemental sur l'evolution du climat/Intergovernmental Panel on Climate Change-IPCC, C/O World Meteorological Organization, 7bis Avenue de la Paix, CP 2300 CH-1211 Geneva 2 (Switzerland)

Goldreich, Y. (2003), The Climate of Israel. Observation, Research and Applications., KluerAcademic/Plenum Publishers., New York.

Goodess, C. M. (2000), The Construction of Daily Rainfall Scenarios for Mediterranean Sites Using a Circulation-Type Approach to Downscaling. Ph.D. thesis, University of East Anglia, Norwich.

Hanggi, P. J. M., Kuttel, M., Wanner, H., Weingartner, R. (2011), Weather type-related trend analysis of precipitation in Switzerland., Hydrol Wasserbewirts, 55, 140-154.

Hess, P., and Brezowsky, H. (1977). "Katalog der Grosswetterlagen Europas 1881- 1976," in Berichte des Deutschen Wetterdienst, No. 113 (Offenbach am Main: Selbstverlag des Deutschen Wetterdienstes).

Hope, P., Drosdowsky, W., and Nicholls, N. (2006), Shifts in the synoptic systems influencing southwest Western Australia, Clim Dyn, 26 (7-8), 751-764.

Huang, A., Zhou, Y., Zhang, Y., Huang, D., Zhao, Y., and Wu, W. (2014), Changes of the annual precipitation over central Asia in the twenty-first century projected by multimodels of CMIP5, Journal of Climate, 27, 6627-6646.

Huth, R., Beck, C., Philipp, A., Demuzere, M., Ustrnul, Z., Cahynová, M., Kyselý, J., and Tveito, O. E. (2008), Classifications of Atmospheric Circulation Patterns, Annals of the New York Academy of Sciences, 1146 (1), 105-152.

IPCC (2007), Climate Change 2007, The Physical Science Basis. Contribution of Working Group I to the Fourth Assessment Report of the Intergovernmental Panel on Climate Change. Solomon, S., D. Qin, M. Manning, Z. Chen, M. Marquis, K.B. Averyt, M. 
Tignor and H.L. Miller (eds.). Cambridge University Press, Cambridge, United Kingdom and New York, NY, USA, 996 pp.

IPCC (2013), Climate Change 2013: The Physical Science Basis. Contribution of Working Group I to the Fifth Assessment Report of the Intergovernmental Panel on Climate Change (Stocker, T.F., D. Qin, G.-K. Plattner, M. Tignor, S. K. Allen, J. Boschung, A. Nauels, Y. Xia, V. Bex and P.M. Midgley (eds.)). Cambridge University Press, Cambridge, USA.

Jones, P. D., Hulme, M., and Briffa, K. R. (1993), A comparison of Lamb circulation types with an objective classification scheme, International Journal of Climatology, 13 (6), 655663.

Kalnay, E. K. M., Kistler, R., Collins, W., Deaven, D., Gandin, L., Iredell, M., Saha, S., White, G., Woollen, J., Zhu, Y., Leetmaa, A., Reynolds, R., Chelliah, M., Ebisuzaki, W., Higgins, W., Janowiak, D., Mo. K. C., Ropelewski, C., Wang, J., Jenne, R., and Joseph, D. (1996), The NCEP/NCAR 40-year reanalysis project, Bulletin of the American Meteorological Society, 77, 437-471.

Kwarteng, A. Y., Dorvlo, A. S., and Kumar, G. T. V. (2009), Analysis of a 27-year rainfall data (1977-2003) in the Sultanate of Oman. Int. J. Climatol. 29(4): 605-617.

Leng, G., Tang, Q., and Rayburg, S. (2015), Climate change impacts on meteorological, agricultural and hydrological droughts in China, Global and Planetary Change, 126, 2334.

Littmann, T. (2000), An empirical classification of weather types in the Mediterranean Basin and their interrelation with rainfall, Theor Appl Climatol, 66 (3-4), 161-171.

Lorenzo, M. N., Taboada, J. J., and Gimeno, L. (2008), Links between circulation weather types and teleconnection patterns and their influence on precipitation patterns in Galicia (NW Spain), International Journal of Climatology, 28 (11), 1493-1505.

Lorenzo, M. N., Taboada, J. J., Gimeno, L. (2011), Changes in Present and Future Circulation Types Frequency in Northwest Iberian Peninsula, PLoS ONE, 6 (1), e16201.

Moss, R. H., Hibbard, K. A., Manning, M. R., Rose, S. K., van Vuuren, D. P., Carter, T. R., Emori, S., Kainuma, M., Kram, T., Meehl, G. A., Mitchell, J. F. B., Nakicenovic, N., Riahi, K., Smith, S. J., Stouffer, R. J., Thomson, A. M., Weyant, J. P., and Wilbanks, T.J. (2010), The next generation of scenarios for climate change research and assessment., Nature, 463, 747-756.

Papadopoulos, A., Paschalidou, A. K., Kassomenos, P. A., and McGregor, G. (2014), On the association between synoptic circulation and wildfires in the Eastern Mediterranean, Theor Appl Climatol, 115 (3-4), 483-501.

Perez, J., Menendez, M., Mendez, F., and Losada, I. (2014), Evaluating the performance of CMIP3 and CMIP5 global climate models over the northeast Atlantic region, Clim Dyn, 43 (9-10), 2663-2680.

Ramos, A. M., Sousa, P., Trigo, R. M., Janeira, M., and Prior, V. (2011), Cloud to ground lightning activity over Portugal and its association with circulation weather types, Atmospheric Research, 101(1-2), 84-101.

Ramos, A. M., Cortesi, N., and Trigo, R. M. (2014), Circulation weather types and spatial variability of daily precipitation in the Iberian Peninsula, Frontiers in Earth Science, 2, doi:10.3389/feart.2014.00025.

Roshan, G. R. L., Khoshakh, F., Azizi, G. H., and Mohammadi, H. (2011), Simulation of temperature changes in Iran under the atmosphere carbon dioxide duplication condition, Journal of Environmental Health Science \& Engineering, 8 (2), 139-152.

Saaroni, H., Halfon, N., Ziv, B., Alpert, P., and Kutiel, H. (2010), Links between the rainfall regime in Israel and location and intensity of Cyprus lows, International Journal of Climatology, 30 (7), 1014-1025. 
Schoof, J. T., and Pryor, S. C. (2003), Evaluation of the NCEP-NCAR reanalysis in terms of synoptic-scale phenomena: a case study from the Midwestern USA, International Journal of Climatology, 23 (14), 1725-1741.

Sillmann, J., Kharin, V. V., Zhang, X., Zwiers, F. W., and Bronaugh, D. (2013), Climate extremes indices in the CMIP5 multimodel ensemble: Part 2. Future climate projections. Journal of Geophysical Research: Atmospheres 118 (6): 2473-2493.

Smith, R.A. and Kummerow, C. D. (2013), A Comparison of in Situ, Reanalysis, and Satellite Water Budgets over the Upper Colorado River Basin. J. Hydrometeor, 14, 888-905.

Taylor, K. E., Stouffer, R. J., and Meehl, G. A. (2012), An overview of CMIP5 and the experiment design, Bull. Amer. Meteor. Soc., 93, 485-498.

Trigo, R. M., and DaCamara, C. C. (2000), Circulation weather types and their influence on the precipitation regime in Portugal, International Journal of Climatology, 20 (13), 15591581.

Türkeş, M., and Erlat, E. (2005), Climatological responses of winter precipitation in Turkey to variability of the North Atlantic Oscillation during the period 1930-2001, Theor Appl Climatol, 81 (1-2), 45-69.

Vicente-Serrano, S. M., and López-Moreno, J. I. (2006), The influence of atmospheric circulation at different spatial scales on winter drought variability through a semi-arid climatic gradient in Northeast Spain, International Journal of Climatology, 26 (11), 1427-1453.

Wilks, D. S. (2011), Statistical Methods in the Atmospheric Sciences, 3rd Ed., Academic Press, Amsterdam.

Xoplaki, E., González-Rouco, J., Gyalistras, D., Luterbacher, J., Rickli, R., and Wanner, H. (2003), Interannual summer air temperature variability over Greece and its connection to the large-scale atmospheric circulation and Mediterranean SSTs 1950-1999, Clim Dyn, $20(5), 537-554$. 
Table 1. Characteristics of the CMIP5 models used in this study for the time period 19752100*. Atmospheric resolution (Lat $\times$ Lon) is shown as the number of grids in latitude and longitude, respectively.

\begin{tabular}{|c|c|c|c|c|c|c|}
\hline Model & $\begin{array}{l}\text { Atmospheric } \\
\text { resolution (Lat } \\
\times \text { Lon) } \\
\end{array}$ & $\begin{array}{l}\text { Number } \\
\text { of } \\
\text { layers }\end{array}$ & Institution & $\mathrm{RCP} 2.6$ & $\mathrm{RCP} 4.5$ & $\mathrm{RCP} 8.5$ \\
\hline $\begin{array}{l}\text { BCC-CSM1-1 } \\
(\mathrm{m})\end{array}$ & $1.12^{\circ} \times 1.12^{\circ}$ & L26 & $\begin{array}{l}\text { Beijing Climate Center, China } \\
\text { Meteorological Administration, China }\end{array}$ & $\bullet$ & $\bullet$ & $\bullet$ \\
\hline BNU-ESM & $2.8^{\circ} \times 2.8^{\circ}$ & L26 & Beijing Normal University, China & $\bullet$ & $\bullet$ & $\bullet$ \\
\hline CanESM2 & $2.8^{\circ} \times 2.8^{\circ}$ & L35 & $\begin{array}{l}\text { Canadian Center for Climate Modeling and } \\
\text { Analysis, Canada }\end{array}$ & $\bullet$ & $\bullet$ & $\bullet$ \\
\hline CCSM4 & $0.94^{\circ} \times 1.25^{\circ}$ & L26 & $\begin{array}{l}\text { National Center for Atmospheric Research, } \\
\text { USA }\end{array}$ & • & $\bullet$ & $\bullet$ \\
\hline CNRM-CM5 & $1.4^{\mathrm{o}} \times 1.4^{\mathrm{o}}$ & L31 & $\begin{array}{l}\text { Center National de Recherches } \\
\text { Meteorologiques, Meteo-France, France }\end{array}$ & • & • & $\bullet$ \\
\hline CSIRO-Mk3-6-0 & $1.9^{\circ} \times 1.9^{\circ}$ & L18 & $\begin{array}{l}\text { Australian Commonwealth Scientific and } \\
\text { Industrial } \\
\text { Research Organization, Australia }\end{array}$ & $\bullet$ & $\bullet$ & $\bullet$ \\
\hline FGOALS-s2 & $1.7^{\circ} \times 2.8^{\circ}$ & L26 & $\begin{array}{l}\text { Institute of Atmospheric Physics, Chinese } \\
\text { Academy of Sciences, China }\end{array}$ & $\bullet$ & $\bullet$ & $\bullet$ \\
\hline GFDL-CM3 & $2^{\circ} \times 2.5^{\circ}$ & L48 & $\begin{array}{l}\text { Geophysical Fluid Dynamics Laboratory, } \\
\text { USA }\end{array}$ & $\bullet$ & $\bullet$ & $\bullet$ \\
\hline GFDL-ESM2M & $2^{\circ} \times 2.5^{\circ}$ & $\mathrm{L} 48$ & $\begin{array}{l}\text { Geophysical Fluid Dynamics Laboratory, } \\
\text { USA }\end{array}$ & $\bullet$ & $\bullet$ & $\bullet$ \\
\hline HadGEM2-ES & $1.25^{\circ} \times 1.9^{\circ}$ & L38 & UK Met Office Hadley Center, UK & $\bullet$ & $\bullet$ & $\bullet$ \\
\hline INM-CM4 & $1.5^{\mathrm{o}} \times 2^{\mathrm{o}}$ & L21 & $\begin{array}{l}\text { Institute for Numerical Mathematics, } \\
\text { Russia }\end{array}$ & - & $\bullet$ & $\bullet$ \\
\hline IPSL-CM5A-LR & $1.9^{\circ} \times 3.75^{\circ}$ & L39 & Institut Pierre-Simon Laplace, France & $\bullet$ & $\bullet$ & $\bullet$ \\
\hline IPSL-CM5A-MR & $1.25^{\circ} \times 2.5^{\circ}$ & L39 & Institut Pierre-Simon Laplace, France & $\bullet$ & $\bullet$ & $\bullet$ \\
\hline MIROC5 & $1.4^{\mathrm{o}} \times 1.4^{\mathrm{o}}$ & $\mathrm{L} 40$ & $\begin{array}{l}\text { Model for Interdisciplinary Research on } \\
\text { Climate, Japan }\end{array}$ & $\bullet$ & $\bullet$ & $\bullet$ \\
\hline MIROC-ESM & $2.8^{\circ} \times 2.8^{\circ}$ & L80 & $\begin{array}{l}\text { Model for Interdisciplinary Research on } \\
\text { Climate, Japan }\end{array}$ & $\bullet$ & $\bullet$ & $\bullet$ \\
\hline $\begin{array}{l}\text { MIROC-ESM- } \\
\text { CHEM }\end{array}$ & $2.8^{\circ} \times 2.8^{\circ}$ & L80 & $\begin{array}{l}\text { Model for Interdisciplinary Research on } \\
\text { Climate, Japan }\end{array}$ & $\bullet$ & $\bullet$ & $\bullet$ \\
\hline MPI-ESM-LR & $1.9^{\circ} \times 1.9^{\circ}$ & L47 & $\begin{array}{l}\text { Max Planck Institute for Meteorology, } \\
\text { Germany }\end{array}$ & - & $\bullet$ & $\bullet$ \\
\hline MPI-ESM-MR & $1.9^{\circ} \times 1.9^{\circ}$ & L95 & $\begin{array}{l}\text { Max Planck Institute for Meteorology, } \\
\text { Germany }\end{array}$ & $\bullet$ & $\bullet$ & $\bullet$ \\
\hline MRI-CGCM3 & $1.1^{\circ} \times 1.1^{\circ}$ & L48 & Meteorological Research Institute, Japan & $\bullet$ & $\bullet$ & $\bullet$ \\
\hline NorESM1-M & $1.9^{\circ} \times 2.5^{\circ}$ & L26 & Norwegian Climate Center, Norway & • & $\bullet$ & $\bullet$ \\
\hline
\end{tabular}


843 Table 2. The criteria used to define the different weather types, based on total shear vorticity (Z) and resultant flow (F).

845

\begin{tabular}{ll}
\hline Description (acronym) & Calculation \\
\hline Directional (N,NE,E,SE,S,SW,W,NW) & $|\mathrm{Z}|<\mathrm{F}$ \\
Cyclonic (C) & $|\mathrm{Z}|>2 \mathrm{~F}, \mathrm{Z}>0$ \\
Anticyclonic (A) & $|\mathrm{Z}|>2 \mathrm{~F}, \mathrm{Z}<0$ \\
Hybrid cyclonic (HYC) & $\mathrm{F}<|\mathrm{Z}|<2 \mathrm{~F}$ and $\mathrm{Z}>0$ \\
Hybrid anti-cyclonic (HYA) & $\mathrm{F}<|\mathrm{Z}|<2 \mathrm{~F}$ and $\mathrm{Z}<0$ \\
\hline
\end{tabular}

846

847

848

849

850

851

852

853

854

855

856

857

858

859

860

861

862

863

864

865

866

867

868

869

870

871

872

873 


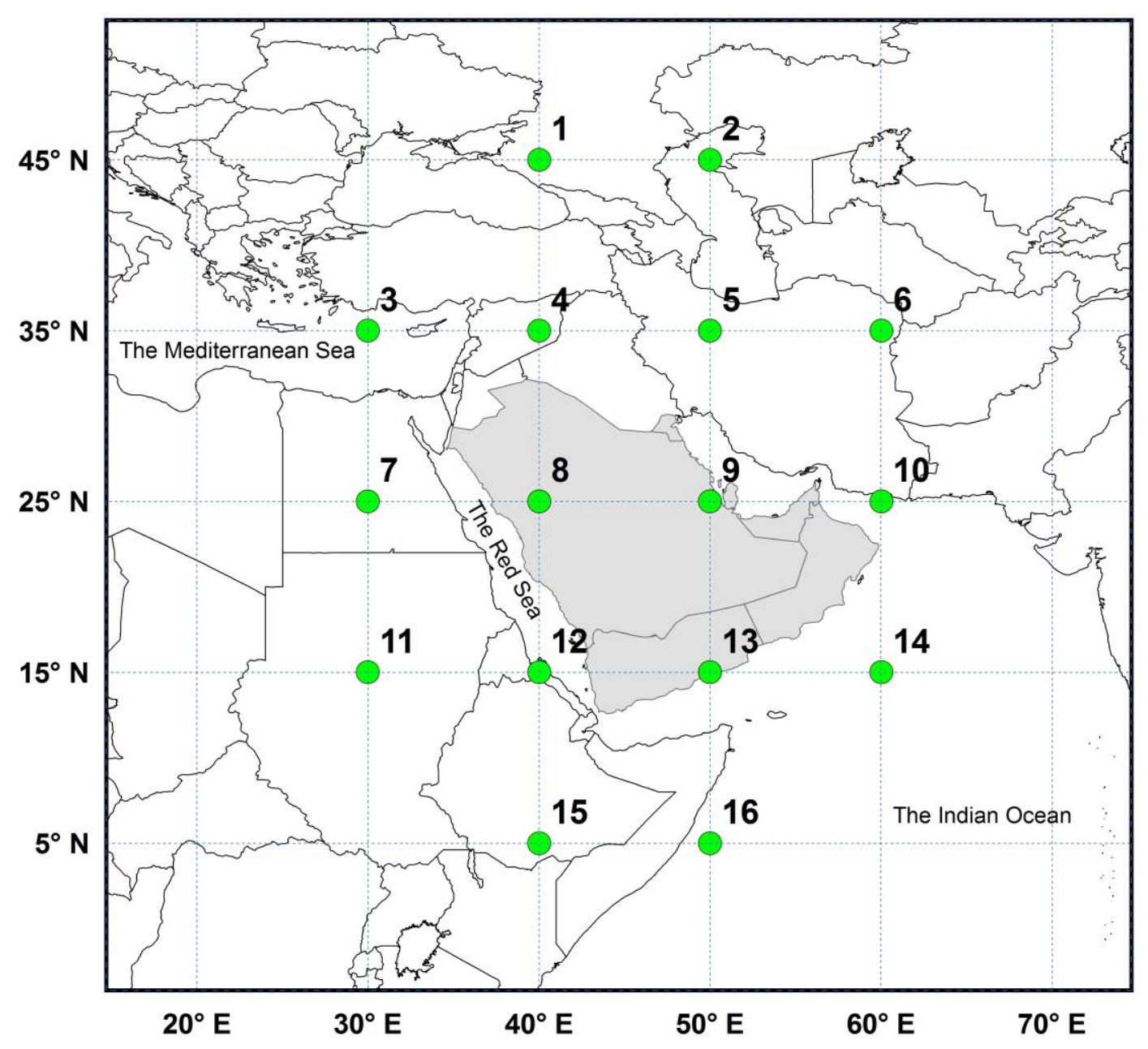

Figure 1. Location of the study domain and the spatial distribution of the 16 points (1-16) used in the automated circulation-typing. 

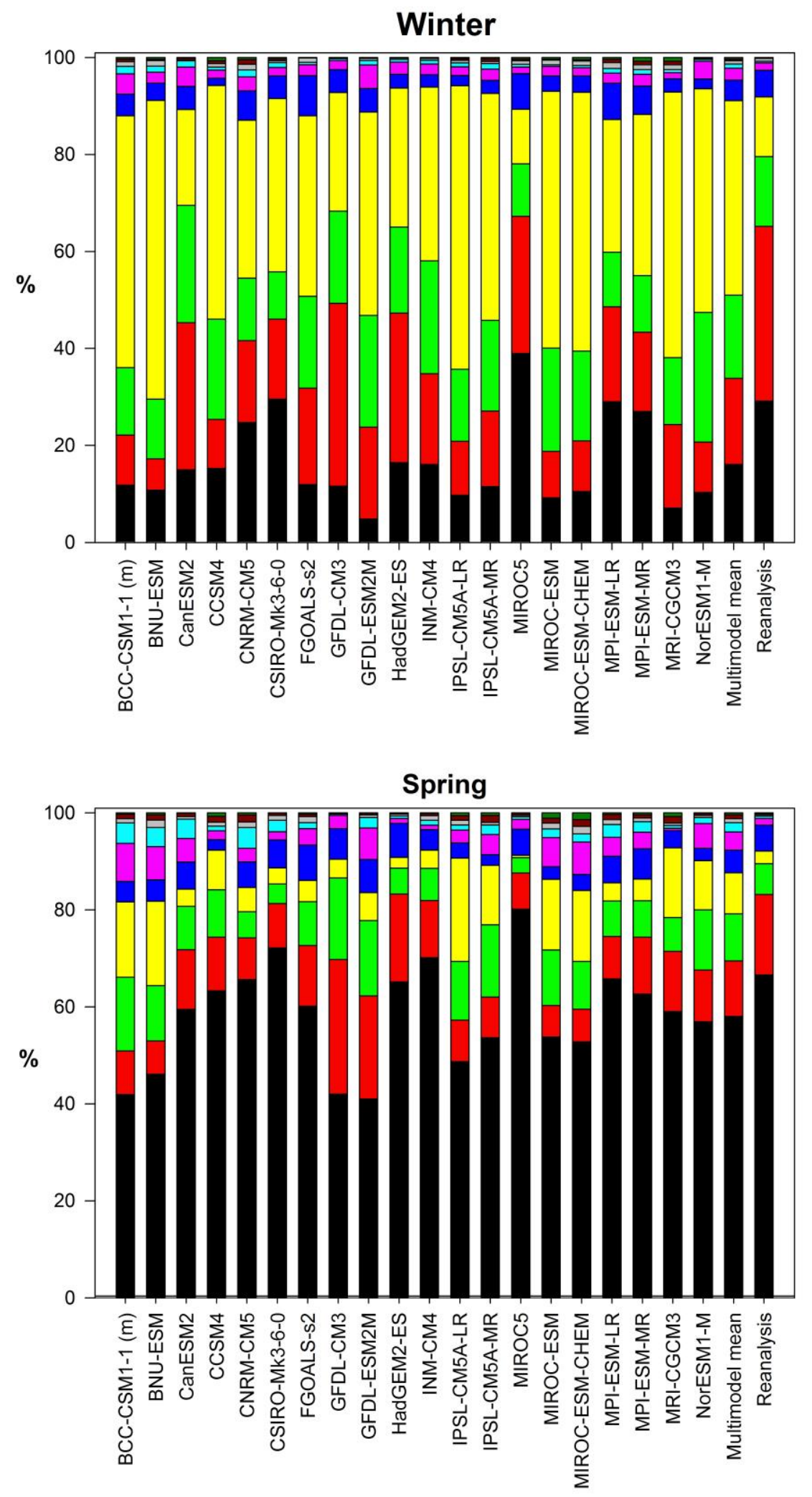

Figure 2: Relative frequency $(\%)$ of the circulation types calculated for winter and spring using the NCEP/NCAR reanalysis and the CMIP5 ensemble data during the period 19752000. The multi-model mean is also provided. In this figure and all subsequent figures, weather types are presented in an order that follows their annual frequency according to the NCEP/NCAR data during the reference period (1975-2000). 

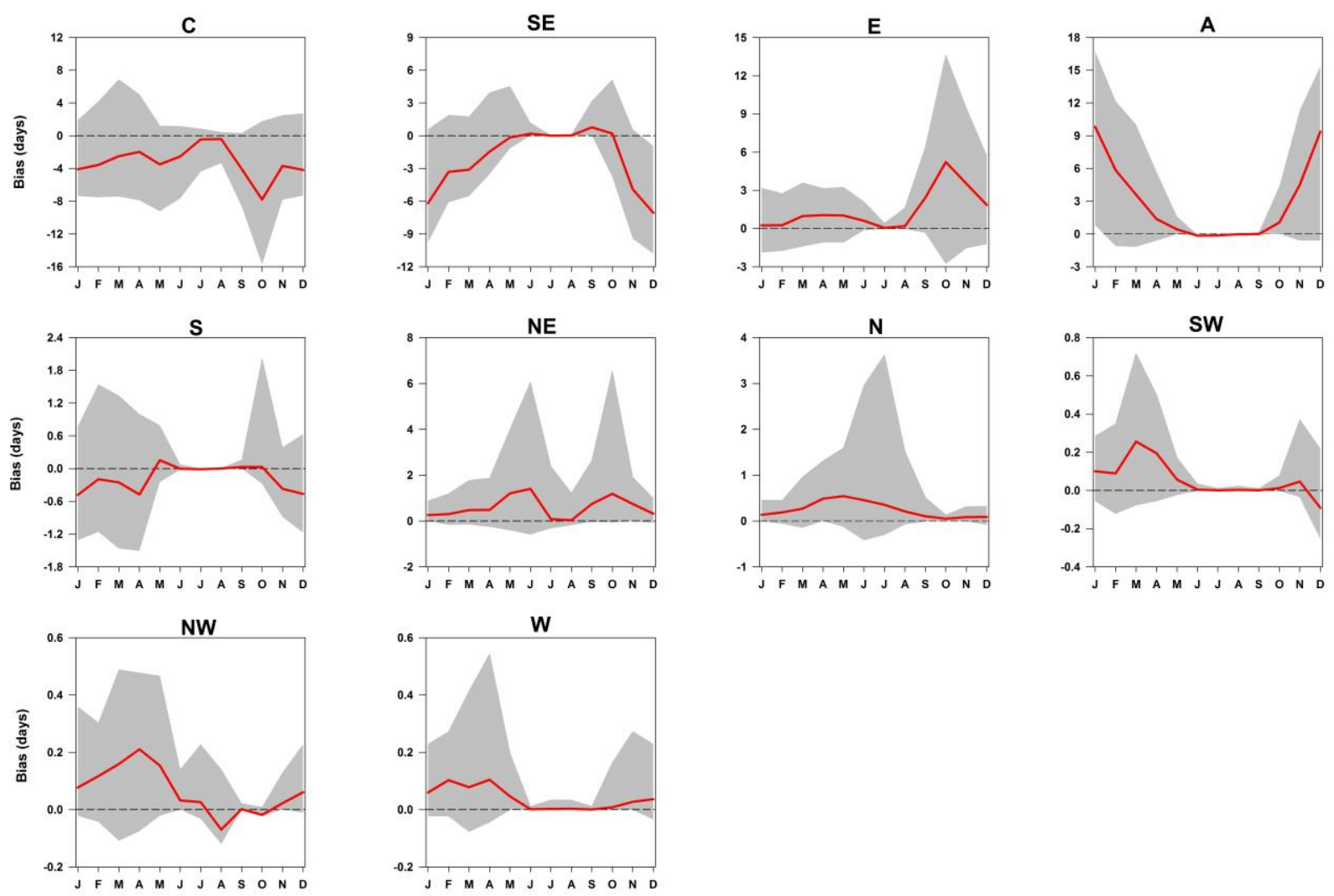

Figure 3. Multi-model mean monthly bias (days) for each individual weather type calculated for the period 1975-2000, represented by the red line. The gray-shaded area shows the amplitude of the uncertainties, represented by the upper (99) and lower (1) limits of the percentiles.

904

905

906

907

908

909

910

911

912 


\section{Winter}
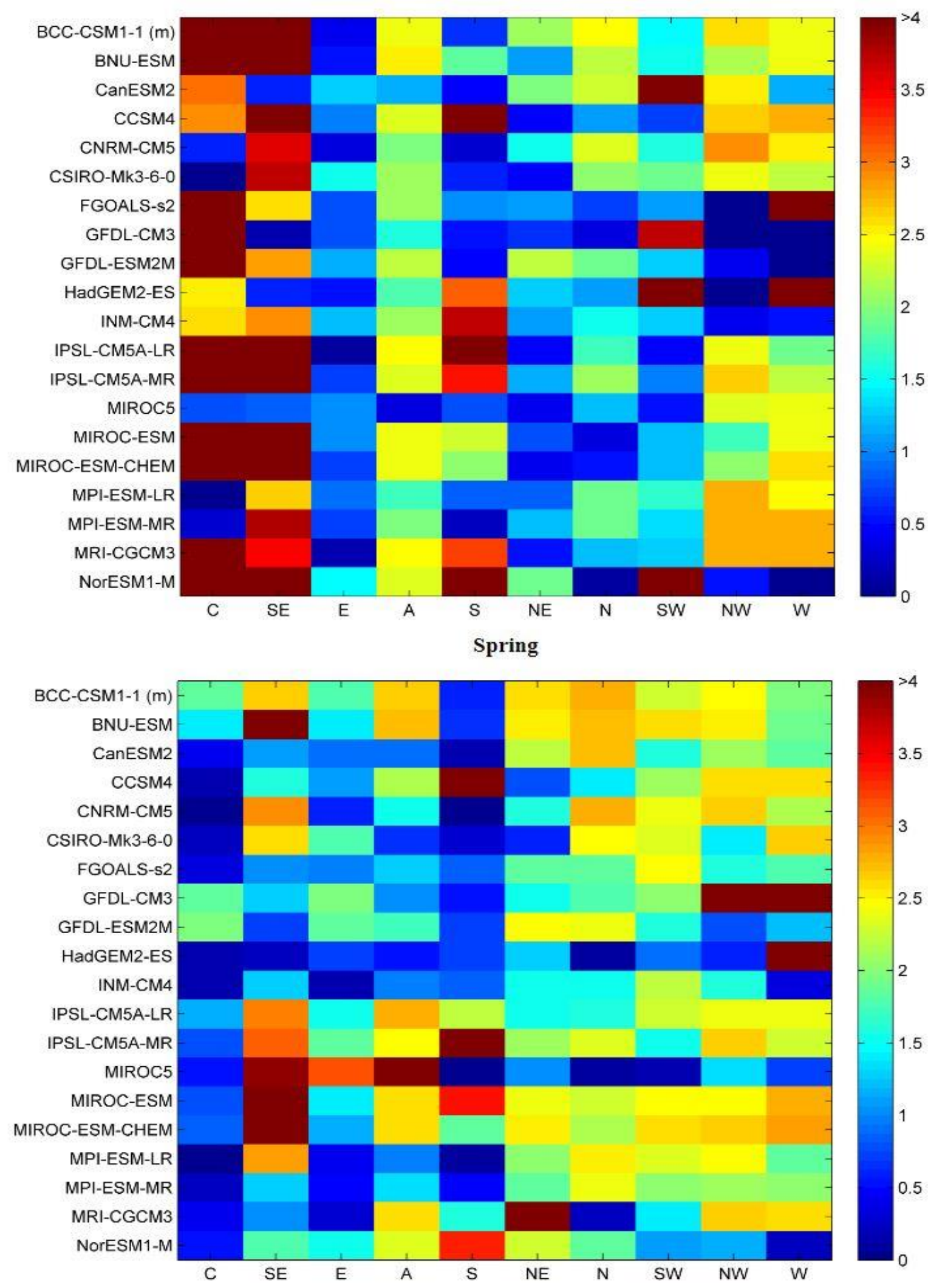

Figure 4: A portrait diagram showing the performance of each single model for winter and spring simulations of weather types during the period 1975-2000, using the Scatter 
Winter
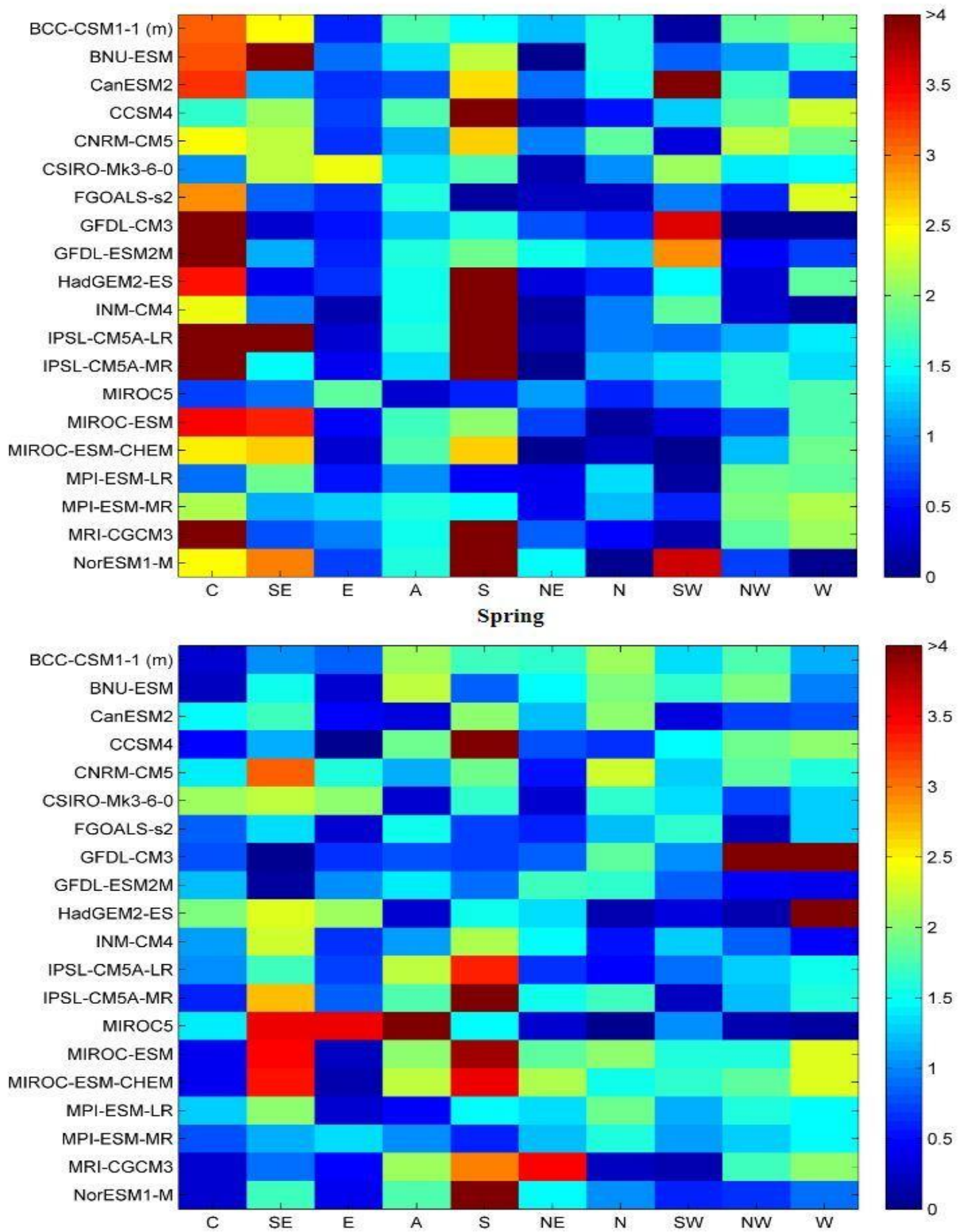

Figure 5: A portrait diagram showing the performance of each single model for winter and spring simulations of weather types during the period 1975-2000, using Standard deviation Scatter Index (stdevSI). Lower stdevSI indicates better performing models and vice versa. 

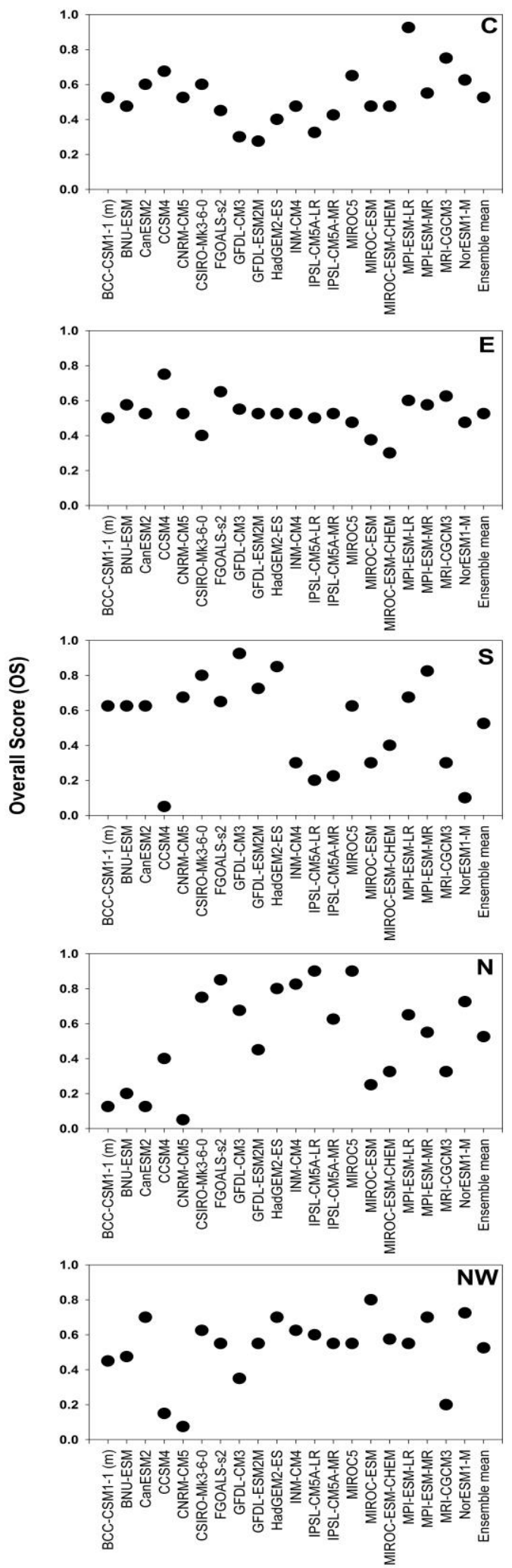
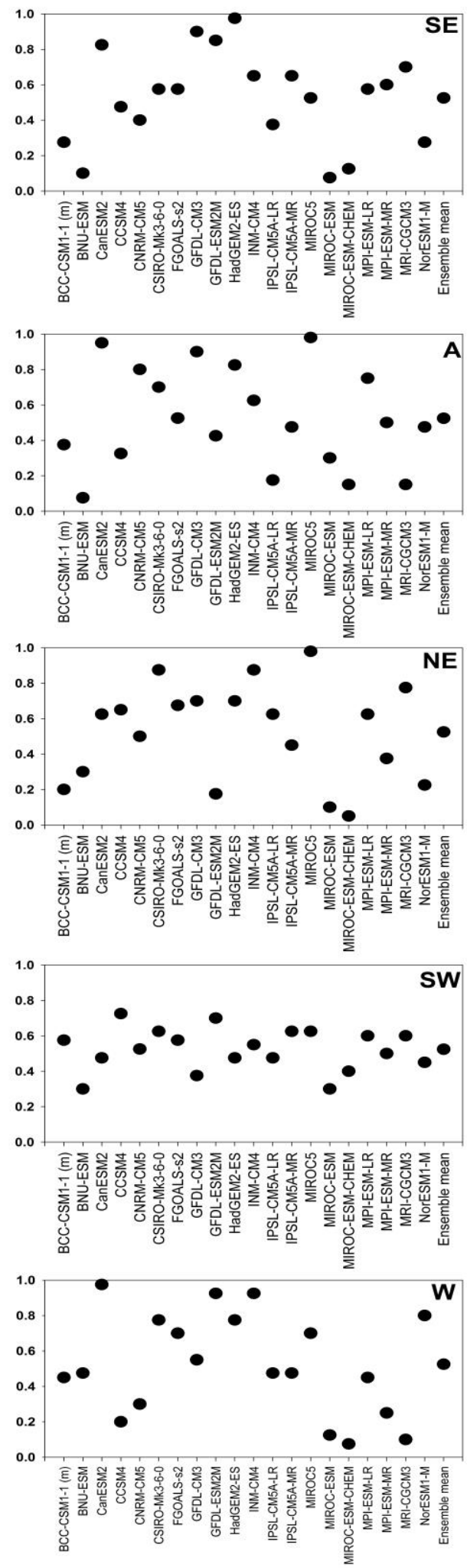

Figure 6: The combined skill of the 20 CMIP5 models in simulating the statistical characteristics (mean and standard deviation) of the ten weather types during the period from 1975 to 2000. 

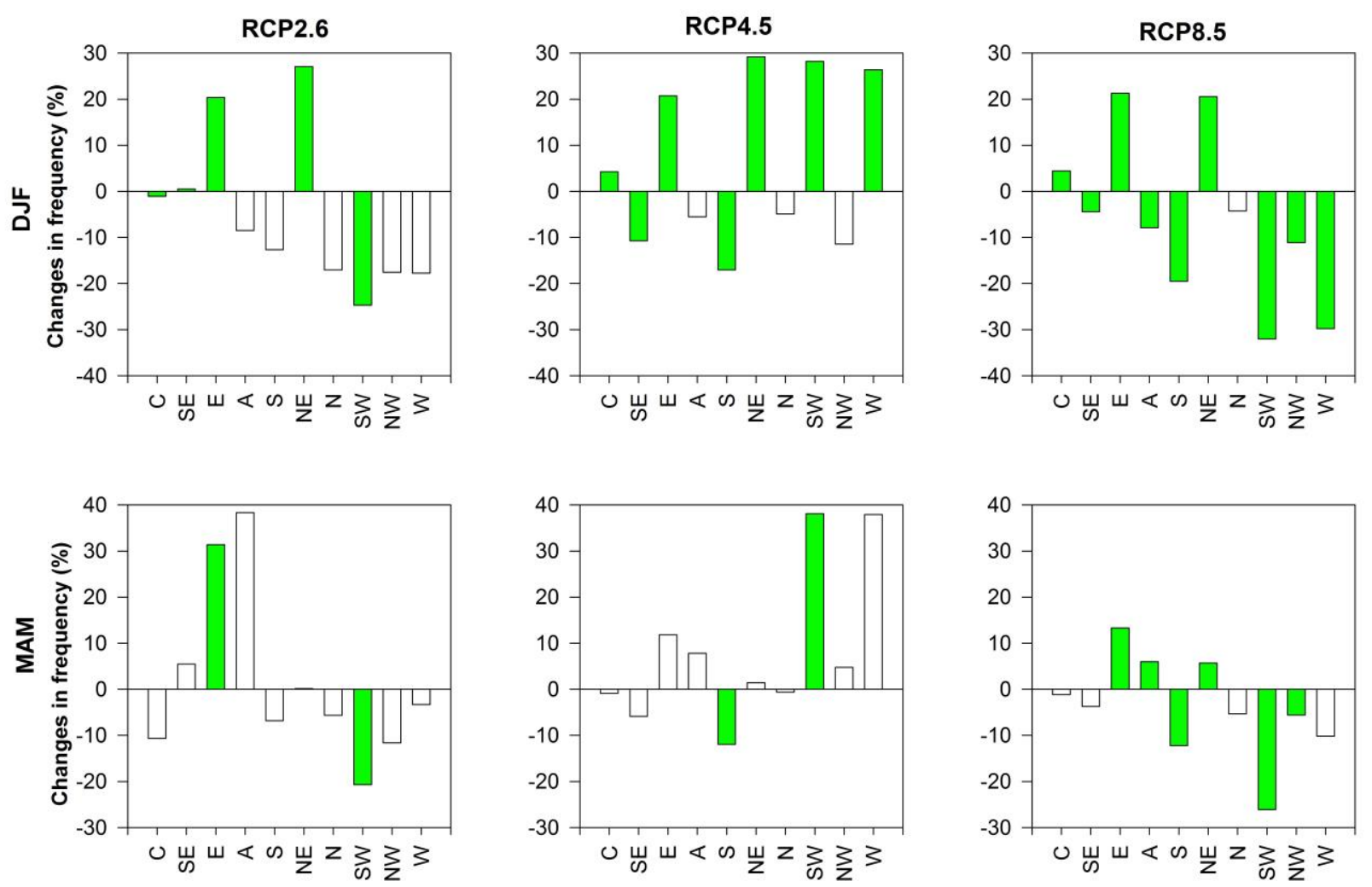

Figure 7: Projected changes (\% of days) in the mean frequency of the ten weather types over the time period 2035-2060, computed as differences relative to the base period (19752000) for RCP2.6 (left panels), RCP4.5 (central panels) and RCP8.5 (right panels). The statistical significance of the differences between the base period and future simulations was assessed using Wilcoxon signed-rank test $(p<0.05)$. 

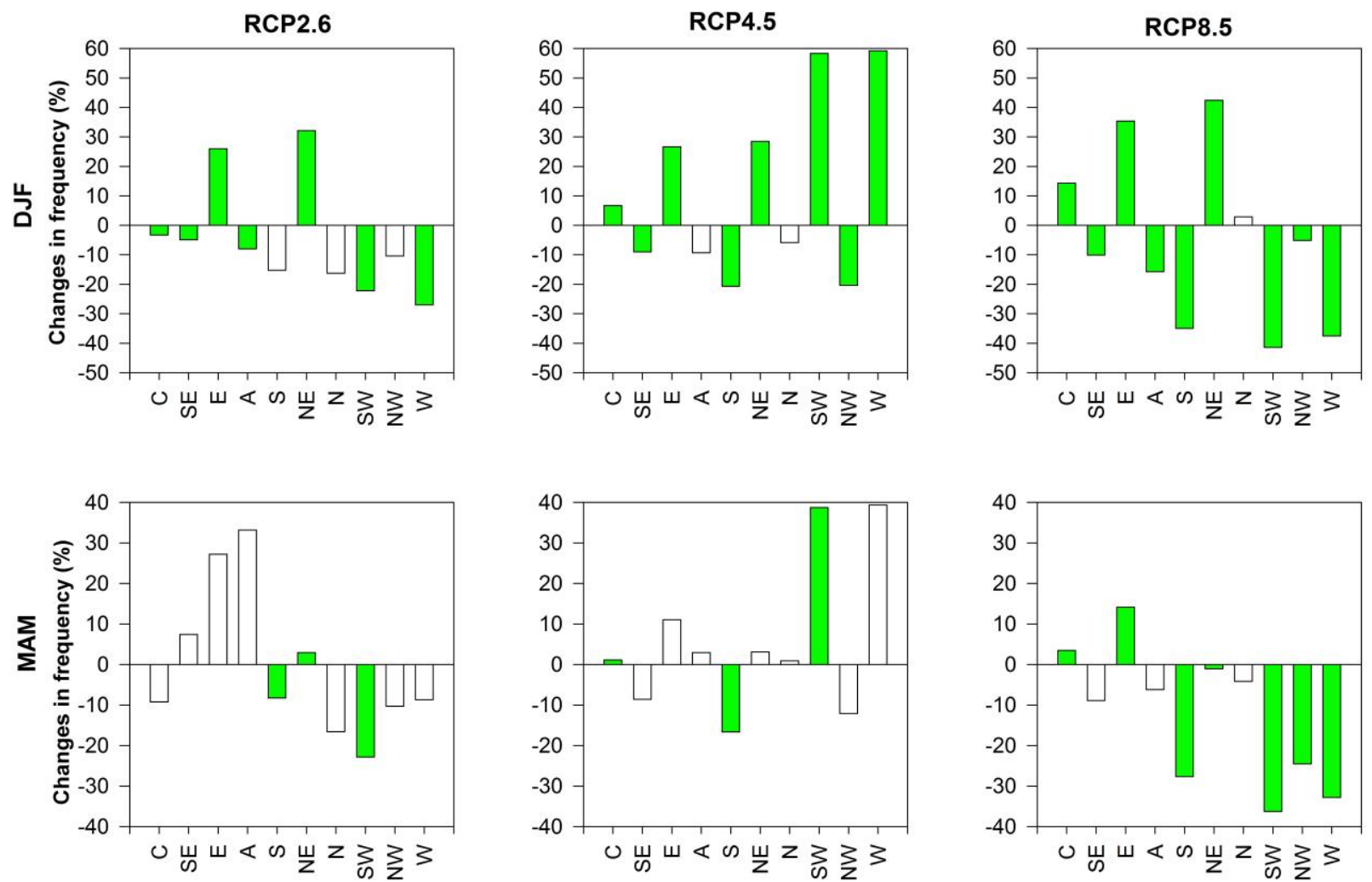

Figure 8: Projected changes (\% of days) in the mean frequency of the ten weather types over the time period 2075-2100, computed as differences relative to the base period (19752000) for RCP2.6 (left panels), RCP4.5 (central panels) and RCP8.5 (right panels). The statistical significance of the differences between the base period and future simulations 

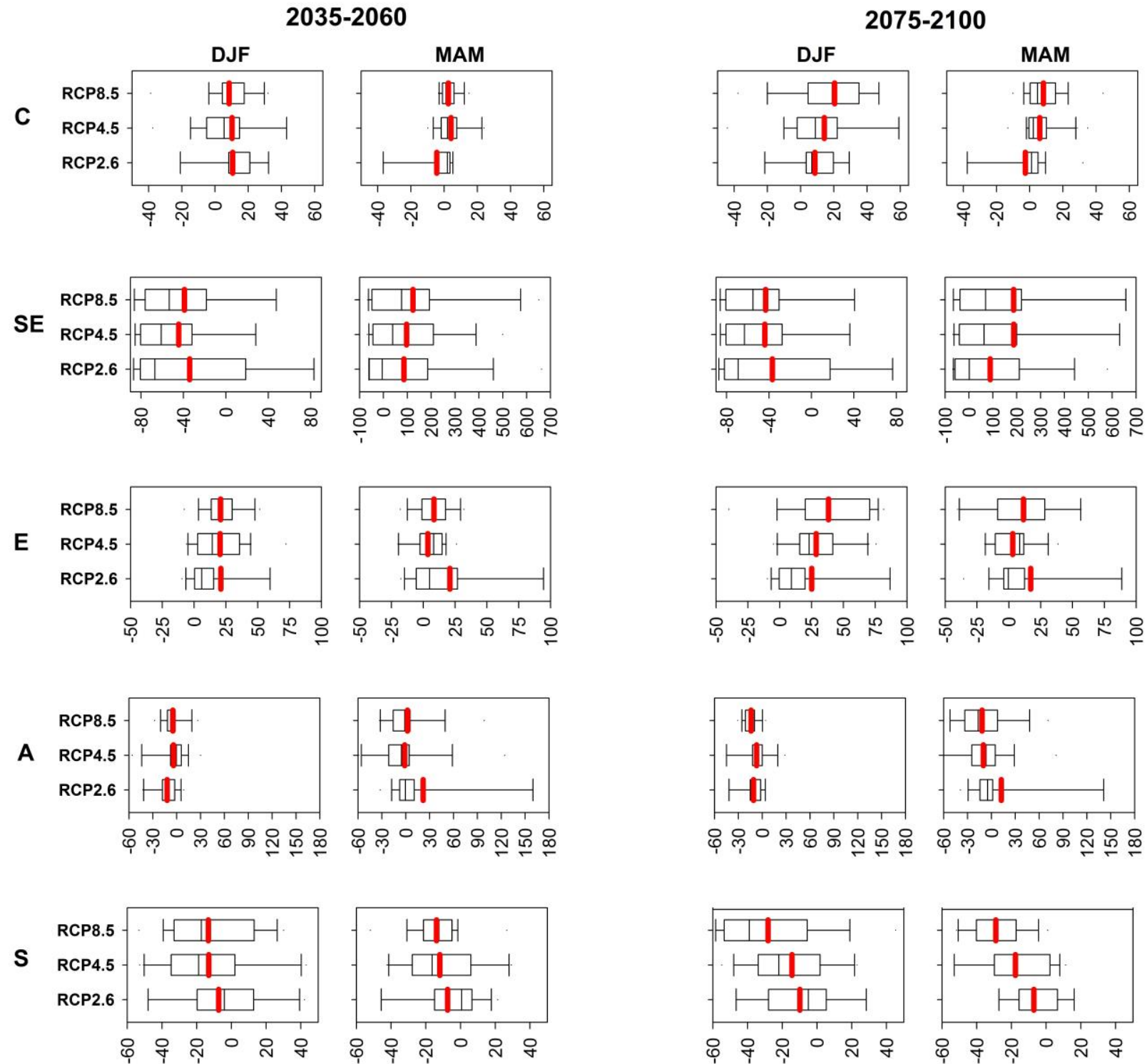
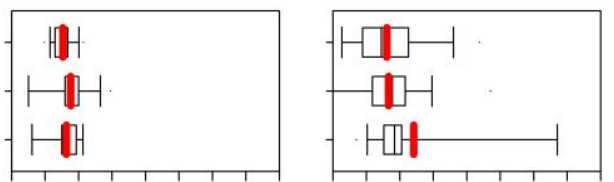

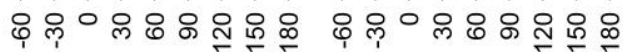
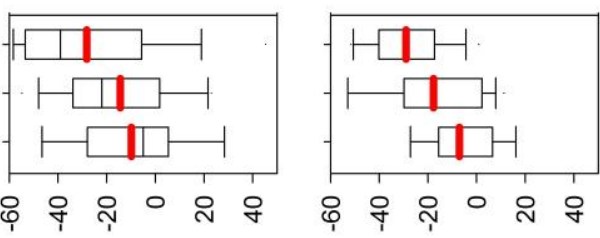

Figure 9: Future changes $(\%)$ in the mean frequency of the circulation types for the near (2035-2060) and far future (2075-2100) using the three RCP scenarios. The mean frequency of the circulation types is displayed relative to the $1975-2000$ base period. The central black line shows the multi-model median, whereas the red line indicates the multimodel mean. The vertical lines of each plotted boxplot illustrate the 10th, 25th, 75 th and 90th quantiles, respectively. The interquartile model spread is represented by the range between the 25 th and 75 th quantiles. 